\title{
Tele-Healthcare Unit for Remote Patient Monitoring
}

\author{
Vasujadevi Midasala, H Mani Sai Prakash, T abhilash, L Rohit
}

\begin{abstract}
Tele-health is characterized as the usage of electronic data and broadcast using telecommunication advancements to help and advance long-distance clinical medicinal services, patient and expert long-distance clinical health care, patient and professional health education, public healthmonitoring and health administration. In this research, the proposed system that uses Sensors to monitor patient's health and uses internet to alert the practitioner and family members in case of emergency. It is capable of monitoring health status of the patient at home, which is at remote location also. If system identifies any parameter is beyond the normal range temperature, the health care unit gives continuous alertation about the patients' status over Internet and also shows details of heartbeat \& temperature of patient continuously using the IoT.
\end{abstract}

Keywords : Telecommunications, Tele-health, Tele-Medicine, Public Health, IoT.

\section{INTRODUCTION}

Telemedicine alludes to the practice of caring for patients remotely without communicating with the doctor physically, i.e. the doctor \& patients are not actually present with each other. A technology which makes healthcare as more accessible, cost-effective \& also enhances the patient engagement is called as telemedicine. Doctors \& patients can share data continuously starting with one PC screen then onto the next [1]. Furthermore, they can even monitor and process readings from medicinal gadgets from a distant area. Utilizing telemedicine programming, patients can see a specialist for conclusion and treatment without hanging tight for an arrangement. Patients can get counseled by the doctor at the solace of their home itself. There are additionally some telemedicine [2] is directed with compact telemedicine units that incorporate a PC and portable restorative gadgets, for example, ECGs or indispensable signs screens.

\section{Telehealth:}

HealthIT.gov defines tele-health [3] as the utilizes the electronic sensors to collect the data \& telecommunications technologies to achieve long-distance clinical health care and health administration. In this research, the proposed system that uses Sensors to monitor patient's health and uses internet to alert the practitioner and family members in case of

Revised Manuscript Received on December 30, 2019.

* Correspondence Author

Vasujadevi Midasala*, Assistant Professor, Department of ECE, Koneru Lakshmaiah Education Foundation, Vaddeswaram, Guntur.

Email: vasujadevi@gmail.com

H Mani Sai Prakash, T abhilash, L Rohith, Department of ECE, Koneru Lakshmaiah Education Foundation, Vaddeswaram, Guntur.

(C) The Authors. Published by Blue Eyes Intelligence Engineering and Sciences Publication (BEIESP). This is an open access article under the CC BY-NC-ND license (http://creativecommons.org/licenses/by-nc-nd/4.0/) emergency. It is capable of keeping monitor of the health status of the patient at home, which is at remote location also.

\section{PROCEDURE}

This health patient monitoring unit is Raspberry pi-3 based system which continuously monitors the patient heartbeat and temperature. The following steps will explore the procedure to successfully monitor the Patients health from anywhere in the world. The basic block diagram of the proposed tele-healthcare unit is shown in figure 1.

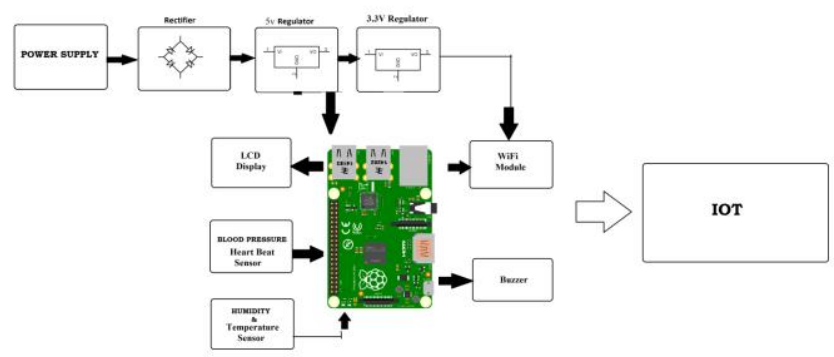

Figure 1: The block diagram \& flow of the proposed tele-healthcare unit

Hardware Set-up:

1. The Raspberry pi cable is to be connected to the raspberry pi- 3 and PCB board, which contains the temperature sensor(DHT-11) and heart beat sensors along with required passive components.

2. Next step is to set the Wi-Fi module with the raspberry pi 3 then, need to insert a Micro SD card with NOOBS software.

3. After Connecting all the hardware tools now connect the LCD screen to PCB board where we can see our required measurements.

4. Now the hardware unit is set as shown in figure 2 .

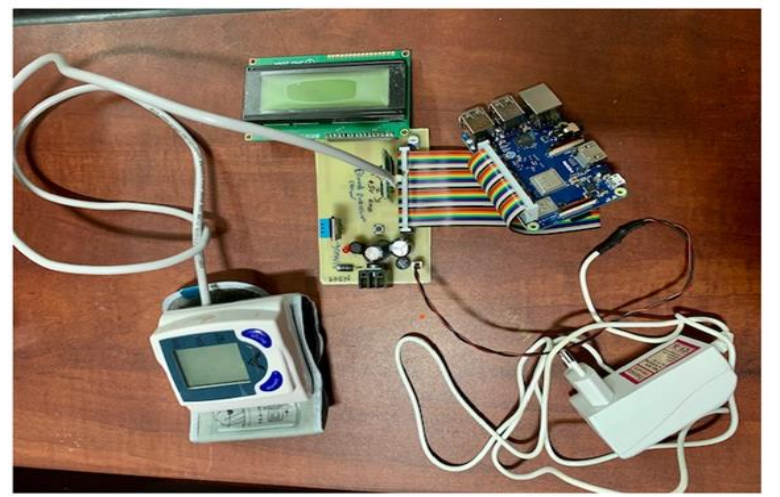

Figure 2: Hardware set-up for proposed tele-healthcare unit 


\section{WORKING PRINCIPLE}

The working condition of the proposed system is shown in figure 3.The sytem uses temperature, Blood Pressure and heartbeat sensing to keep monitor of patient health. The sensors are connected to a Raspberry Pi processor to monitor the status which is also interfaced to a lcd display \& Wi-Fi connection to make the transmission of alerts possible.

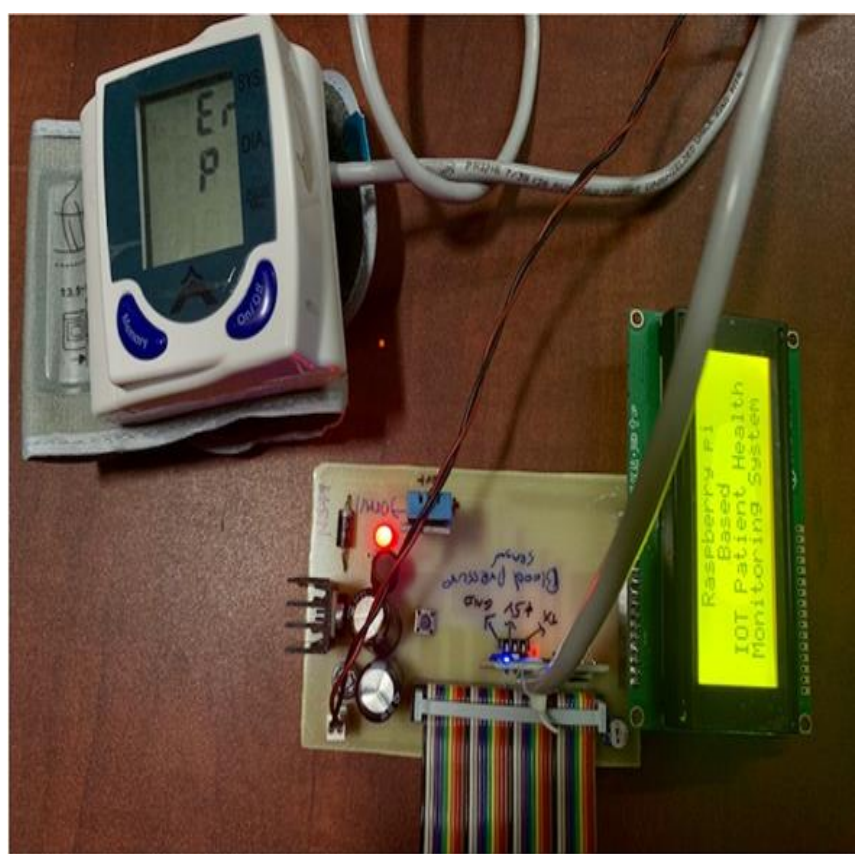

Figure 3: The working condition of the proposed system

\section{Advantages:}

This is a low cost model amounting upto 5000 rupees only where this allows the doctor to just monitor the patient while the patient is at home. This also gives more ease to the people who live in rural areas where they have to travel so many kilometres for just a checkup. This also gives advantage to the middle class or poor people who live in cities with medical condition, as there's no need to pay for the hospital huge amount for living in the hospital rooms.

The doctor simply can monitor his vitals by staying in the hospital itself. When heart beat sensor cross the threshold limit then the system automatically plays the alert buzzer on IoT and it continuously sounds the buzzer till the heart beat level comes in normal range.

\section{RESULTS}

The proposed system output can be observed on the LCD display interms of patient systolic, diastolic and heart beat rate along with room temperature and humidity as shown in figure 4 . The display of the same information over the Internet using IoT is also shown in figure 5.

This information can be accessed by the doctor remotely, and can give necessary instructions to the practitioner for the emergency condition. It helps the rural area people to get continuous monitoring and relevant suggestions in case of needy situations.

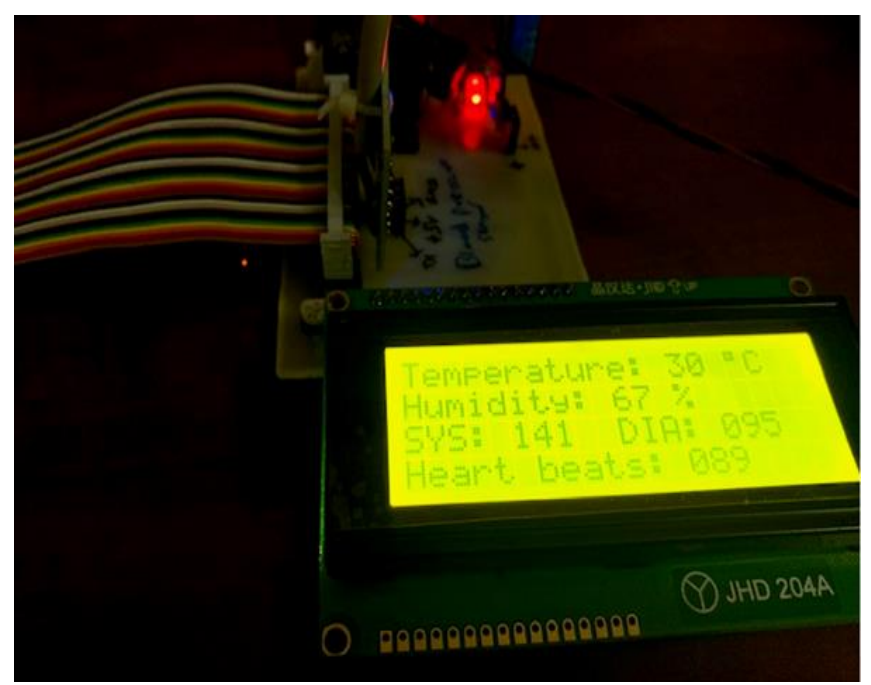

Figure 4: patient systolic, diastolic and heart beat rate on proposed tele healthcare Unit

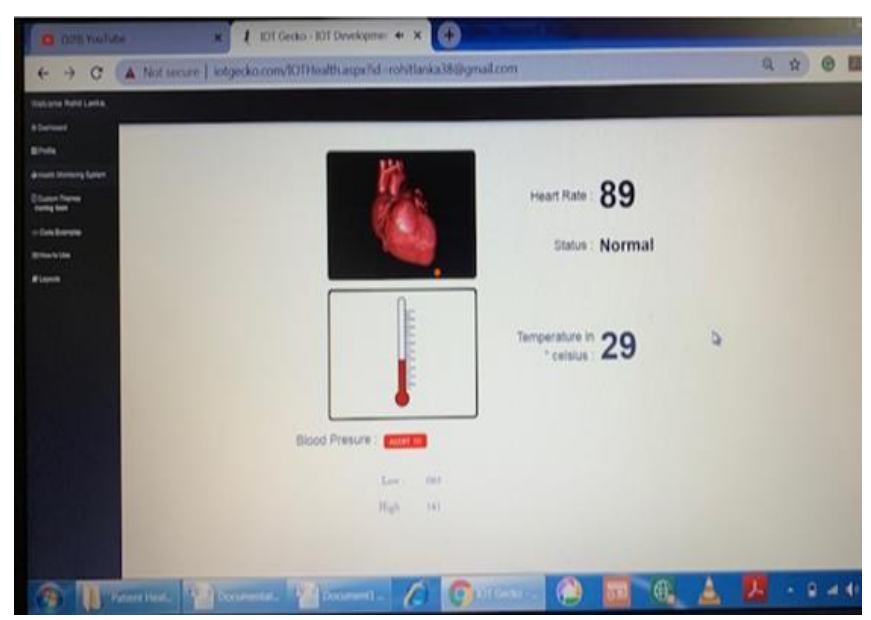

Figure 5: The display of the same patient information over the Internet using IoT

\section{CASE STUDY}

The Blood pressure of patients' of different ages have been observed using the proposed system and tabulated on barchart as shown in figure 6 .

\section{BP AGES}

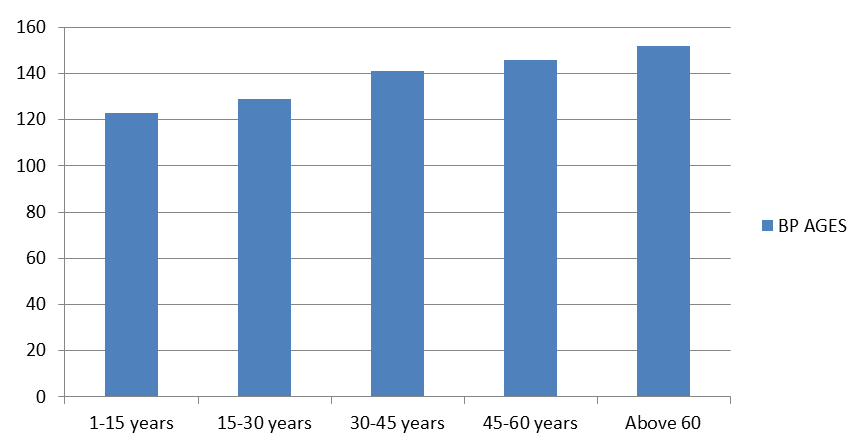

Figure 6: The Blood pressure of patients' of different ages 


\section{CONCLUSION}

The proposed Tele-healthcare Unit is connected according to requirement and the Blood pressure of patients' of different ages have been observed and tabulated

\section{REFERENCES}

1. Jorge Gómez, "Patient Monitoring System Based on IoT: A survy", Computer Netwrks, Vol.54, pp. 2787-2805, 2016.

2. Sneha N. Malokar 1, Samadhan D. Mali2, "Patient Monitoring System Based on IoT using Rasperripy: Key features, application and open issues", Computer Communication, Vol.54, pp., 2016.

3. Vasujadevi Midasala, "Performance Analysis of LEACH Protocol for D2D Commnication in LTE-Advanced Network", IEEE 2016, ISBN: 978-1-5090-0612-0 (IEEE Xplore), 978-1-5090-0610-6 (CD ROM), 978-1-5090-0611-3 (Print), pp. 1-5.

4. Vasujadevi M., Naga Kishore B.S., Batchu M., Vijay Sai Tejan B., Performance optimization of multband micrstrip patch antenna by incorprating EBG structurs, JARDCS, Vol:2017, pp: 2066-2075, ISSN: 1943023X.

5. Vasujadevi M, P Siddaiah "Effect of DGS on 1x2 Linear Array Antenna" International Journal of Innovative Technology and Exploring Engineering, volume 8 (5)-2019.

6. Vasujadevi M, BVN Vyshnavi, P Charan Sai "Design of Rectangular DRA for IOT Applications" International Journal of Innovative Technology and Exploring Engineering, volume 8 (5)-2019.

7. Vasujadevi M, J Lavanya "Design of Spiral antenna for Multiband Applications" International Journal of Innovative Technology and Exploring Engineering, volume 8 (5)-2019.

8. Vasujadevi Midasala, P siddaiah, "Design Simulation of array DGS using HFSS", International Journal of Innovative Technology and Exploring Engineering, volume 8 (3)-2019: pp. 47-49.

\section{AUTHORS PROFILE}

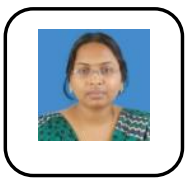

Er. Vasujadevi Midasala, submitted a Ph.D. degree in Antennas and Communications from JNTUA Ananthapuramu. She is working as an assistant professor from Department of ECE in Koneru Lakshmaiah Education Foundation. Her research interest is the Internet of Things, Antennas and Communications, VLSI Design, Image Processing and Machine Learning.

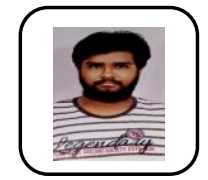

Mr. H Mani Sai Prakash, Final year Student of KL University, ECE Department. He is interested research area is in Internet of Things.

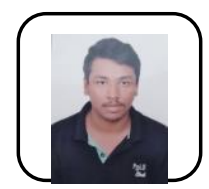

Mr. T Abhilash, Final year Student of KL University, ECE Department. He is interested research area is in Internet of Things and VLSI systems.

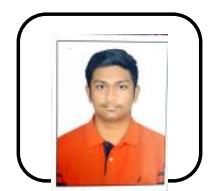

Mr. Rohit Lanka, Final year Student of KL University, ECE Department. He is interested research area is in Internet of Things. 